\title{
Prey Diversity of Common Leopard and Factors Affecting Human-Common Leopard Conflict in Community Forests of Arghakhanchi District Nepal Ashra Kunwar ${ }^{1} \&$ Narayan Prasad Koju ${ }^{2}$
}

${ }^{1}$ Graduate Student, Department of Environmental Science, Goldengate International College (GGIC), Kathmandu, Nepal

${ }^{2}$ Assistant Professor, Centre for Postgraduate Studies, Nepal Engineering College, Pokhara University, Nepal

\section{Corresponding Author}

Narayan Prasad Koju

Email: npkoju.2003@gmail.com

\section{ABSTRACT}

Conflict between human and wildlife is one of the main threats to the continued survival of many species in different parts of the world, and is also a significant threat to local human populations. As human populations expand and natural habitats shrink, people and animals are increasingly coming into conflict over living space and food. People lose their crops, livestock, property, and sometimes even their lives. Initially, with the use of structured interviews and few key informant survey, 120 households were selected for questionnaire in which 25 were from victim's family and 95 from Sandhikharka village and the city areas using both purposive and random sampling method. Key informant interviews were also taken with officers of Division forest office and active members of community forest. Similarly, to access the prey diversity, a total of 9 infrared cameras were installed. As the objective of the research, the result was obtained based on secondary and primary data with the use of structured interviews to quantify attitudes based on 5 questions with the given scores where the scores were added together. At the end, the ANOVA test was carried out with the variances among the control variables influencing the attitude toward leopards while assessing the overall attitudes of people with those scores. The result discusses the mean attitude of illiterate people as negative $(-1.03 \pm 0.14 \mathrm{SE})$ towards leopard. Also, overall mean attitude of literate people was negative $(-1.19 \pm 0.17 \mathrm{SE})$. Total 6750 images were recorded during study period among them only single event of leopard was captured in the camera trap and 72 independent prey images were captured by infrared camera. Mongoose, Wild cat, Rabbit, Porcupine and barking deer were commonly recorded. Rest of photos recorded were human movement, suggesting less prey abundance and higher human activities in study area. PCA analysis regarding factors affecting leopard human conflict suggested that the distance from water source to local people, distance from toilet to home, land use change going on in the study area, scarcity of water source to wildlife inside the forest, distance to graze livestock are major factors having positive impact on human leopard conflict.

\section{KEYWORDS}

Arghakhanchi, Camera trap, Human wildlife conflict, Wildlife, Victims 


\section{INTRODUCTION}

Globally, increase in human populations, increase in resource use and habitat loss are causing human -carnivore conflict (Treves \&Karanth, 2003). Large carnivores occupy large home ranges and often, its dietary requirement overlap with people which in turn forced large carnivores to live in increasing proximity of humans (Linnell \& Anderson,2001). As large carnivores are forced to live in increasing proximity to humans, competition for space and ungulate prey species leads to conflict (Linnell, 2001). Such conflict can be the most important cause of adult carnivore mortality in human dominated landscapes adjoining forest areas (Barlow et al., 2008; Gurung et al., 2007; McDougal et al., 2006).

The Common Leopards (Panthera pardus) is one of the most widely distributed of all big cats (Bailey, 1993). The leopard is categorized as Vulnerable species by the IUCN Red List of Threatened Species (Stein , 2017). It is threatened throughout its range due to habitat degradation, poaching for valuable skin and bone, and persecution as a killer of humans and livestock (Aryal \& Kreigenhofer, 2009). The Conflict between humans and leopards considered as complex issues which is attributed by political and social attitudes, the biology of species, and management actions (Athreya \& Belsare, 2007). Leopard came into conflicts with human by predating other animals especially in areas where natural habitat of leopard has been modified and native prey displaced by domestic live-stocks (Patterson etal.,2004; Selempo et al.,1992; Yaken et al.,1990). Species most exposed to conflicts with people are more prone to extinction (Frank et al., 2007; Ole Ranah et al., 2006; Lindsey et al., 2005; Woodroffe et al., 2004). Livestock depredation is one of the biggest sources of conflict with humans and also a major underlying cause for the disappearance of large cats from considerable areas of their former range (Inskip \& Zimmermann, 2009). Human-leopard conflict attracts great attention as the conflict creates a serious hazard to human welfare(Wang \& Macdonald, 2006).

Arghakhanchi is one of the districts of Province No. 5 in Nepal. The district headquarter is Sandhikharka. The district covers an area of $1,193 \mathrm{~km}^{2}$ and has a population (2011) of 197,632 (National Population and Housing Census, 2011). Its neighboring districts are Palpa in the east, Gulmi in the north, Kapilvastu District in the south and Pyuthan in the west. 


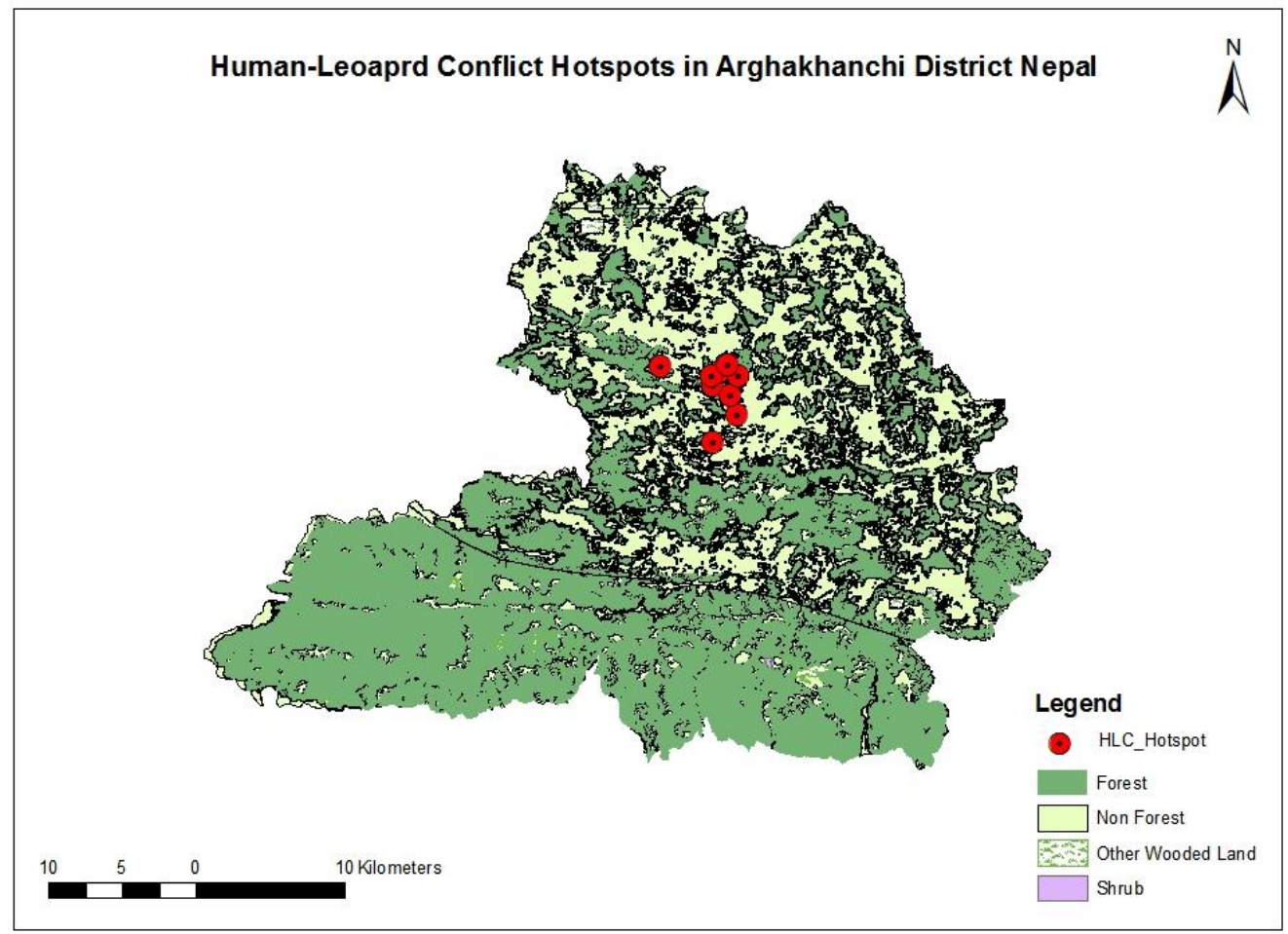

\section{Figure 1: Human - Leopard Conflict Hotspots in Arghakhanchi District Nepal}

Arghakhanchi lies between $27^{\prime} 45^{\prime \prime} \mathrm{N}$ and $28^{\prime} 6 " \mathrm{~N}$ latitude, and $80^{\prime} 45^{\prime \prime} \mathrm{E}$ to $833^{\prime 2} 23^{\prime \prime} \mathrm{E}$ longitude. The altitude of the district varies from 305 to 2515 meter above the sea level. $68 \%$ of the district is in the mountainous Mahabharat Range and the rest is in the Siwalik Hills. About $40 \%$ of the total area is forested.

\section{MATERIALS AND METHODS}

\section{Data collection Methods}

During the collection of data, purposive sampling was done in the study area with a total of $120 \mathrm{HH}$ 's which were surveyed. $120 \mathrm{HH}$ were sampled based on the purposive sampling where all the victims were interviewed along with the non victims and key informant survey which was done. 120 individuals were chosen for the questionnaire survey randomly from both the forest settlement area and the city area. $120 \mathrm{HH}$ were taken from different places of the study areas Seven camera traps were installed near the location with record of previous leopard attack near village, infrared cameras were kept as a purposive sampling. With this approach of the data collection method, samples were independently collected. For the movement of leopard survey, probabilistic survey was done.

\section{Primary Data Source and Collection Method}

\section{Semi structured Questionnaire HH Interview:}

Both quantitative and qualitative information of the communities were collected through semi structured questionnaire, interview (Photograph 1). Randomly sampled HHs from each of the respondent was taken. For $\mathrm{HH}$ interview, questionnaire was asked to each $\mathrm{HH}$.

\section{Key informant Interview:}

Key informant interview was carried out with few key persons as the; community leader (Mr. Dhurba Prasad Chaulagahi), Assistant DFO Divisional forest office of Arghakhanchi (Ms. 
Shila Pokharel), governmental official of VDC interviewed. They were interviewed about the attacks inculcated at Arghakhanchi, awareness schemes done by locals while the attack, governments effort on mitigation and control of HLC, compensation procedure, their attitudes towards leopard in Arghakhanchi.

\section{Stakeholders related to HLC in the Study Area}

Focus group discussion was conducted in the beginning of the research with the local community. Focus group discussion consisted of people from governmental organizations, NGO, police personnel's, news reporter, Divisional forest officers where presentation regarding our research at Arghakhanchi was done where various questions were asked by people attending the seminar was done.

\section{Secondary Data Source}

Secondary data were collected from DFO Arghakhanchi, (Divisional Forest Office, Arghakhanchi). The secondary data collected had the previous attack information's in Sandhikharka, Arghakhanchi. Secondary data collected from the office had information regarding the victims age, date of attack, compensation provided by DFO and more.

\section{Sampling design}

The study has a mixed research approach where both qualitative and quantitative research methods are used. 7 conflict affected wards of Sandhikharka, Arghakhanchi were selected where there were 3000 Households (Central Bureu of Statistics, 2010) based on 3000 households, the sample size was computed at $95 \%$ confidence level and $9 \%$ margin of error by the following formula:

\section{$n=N^{\wedge} 2 * p(1-p) / N^{\wedge} 2+Z^{\wedge} 2 * p(1-p)$}

Where,

$\mathrm{N}=$ total number of household (in selected study area) $=3000$

$\mathrm{n}=$ sample size

$\begin{array}{llllll}\mathrm{Z}= & \text { confidence } & \text { level } & \text { at } & 95 \%, & \end{array}$

4

$\mathrm{p}=$ estimated population proportion $=(0.08)$

$\mathrm{d}=$ margin of error $=(0.05)$

Now, substituting the given values in the formula, we get $n=3000(1.96){ }^{\wedge} 2 * 0.08(1-3000) /$ $3000(0.05) \wedge 2+(1.96) \wedge 2 * 0.08(1-0.08)$

$\mathrm{n}=120$

A questionnaire survey was carried out in 120 Households where cluster sampling design was used during the study. Clusters was indentified; (1) clusters of victim families (2) Cluster of non-victims' families. Two homogenous clusters were made. Within the cluster of non-victim family, simple random sampling was conducted. Total $120 \mathrm{HH}$ were interviewed. Total enumeration in victim's family cluster was carried out in this study with an enumeration of 25 households in the victim's family cluster. Therefore, 25 victims were selected and 95 randomly selected individuals were taken. 


\section{Likert Scale (Attitude Score)}

The structured interviews were helpful in quantifying the overall attitude of people based on the 5 questions. Those questions were later added together. Draft of a short (one sentence) and simple questions with the limitation of the length of the questionnaire was done to minimize chances of interviewee fatigue and the lack of interest. None of the offer options were kept. Designation of the question was done so that there could only be a limited set of answers from it. The sum of scores could range from-5 to 5 with -5 representing the most negative attitude on a relative scale and 6 representing the most positive. Attitude scores of < -1 were considered negative. Scores from -1 to 1 were considered neutral, and scores $>1$ was considered positive. Here, as many people had difficulty in knowing between agree and strongly agree with disagree and strongly disagree, a 5 point Likert scale was not believed to be followed here. There had also been difficulties in understanding the Likert scale which have been reported through the Asian cultures (Mineyama, \& Zhang, 2002). As the questions were asked in Nepali language, the formal interview began by determining whether the interviewee could identify the leopards correctly and can differentiate other similar looking carnivores such as clouded leopards and leopards cat from photographs. If the interviewee correctly identified the predator, the interviewer had preceded the formal interview.

\section{Explanatory Variables}

Two control variables were quantified and analyzed that could potentially influence people's attitudes. This included local people's level of knowledge, based on who reported that in urban, educated people tended to have relatively positive attitudes toward carnivores relative to older, rural, less educated people. Therefore, the difference between attitudes of illiterate and literate respondents was tested. We established 9 correlates of leopards presence in human dominated 5 landscape in questionnaire schedule (Athreya et al., 2015; Bhatia et al., 2015; Bhatnagar et al., 2016; Mishra et al., 2014). These correlates are nearby forest, Home, area under vegetation cover, Garden; Sources of water, Irrigated crop field etc. We, also, recorded 12 forms of human-leopards conflict in our questionnaire schedule. These forms are sighting, Offensive, Defensive, Livestock Attack, Human Attack, Livestock death, Human death, Dead, Human dead, Capture, Captivity, Rescue and Release. We established 8 probable reasons for leopard's presence in human dominated landscape. These are Forest converted to agri-land, Forest converted to settlement, overstocking, Shrinkage of forest habitat, Dogs, livestock and easy prey, Area under vegetation Cover, Irrigated crop field and prey deficiency.

For temporal pattern of leopards, it was divided for 12 months periods in 4 clusters (March-May June-August, September-November, and December-February) and recorded the frequency of leopards presence in human dominated settlement based on subjective judgment of respondents. We included 10 years trend of human-leopards conflict in human dominated landscape based on subjective judgment of respondents.

\section{Camera trapping}

A total number of 7 cameras were kept at the hotspot of Arghakhanchi, Sandhikarkha, Nepal for a total of 6-month period from the month of February 2019 till July 2019. The cameras were installed at: Jerke Deurali, Piyale, Pokharanetta, Ritharukha, dalbari, Talley ghar ko Pokhari, Kura netta and Behore in a grid of $2 * 2 \mathrm{~km}$ square out of total 45 grids on Sandhikharka, we selected 7 forested grids and put camera traps in those grids. 
(Figure 2). The gaps between two cameras were at least $2 \mathrm{~km}$ away. Cameras were installed above $30 \mathrm{~cm}$ (3 meters) from ground wildlife trail or bush near village for the safety of camera because the cameras were installed near the village. The camera trap model to capture this particular leopard was Cuddle Back Trail camera which was kept in 10 seconds interval time for the click of the carnivore and its prey.

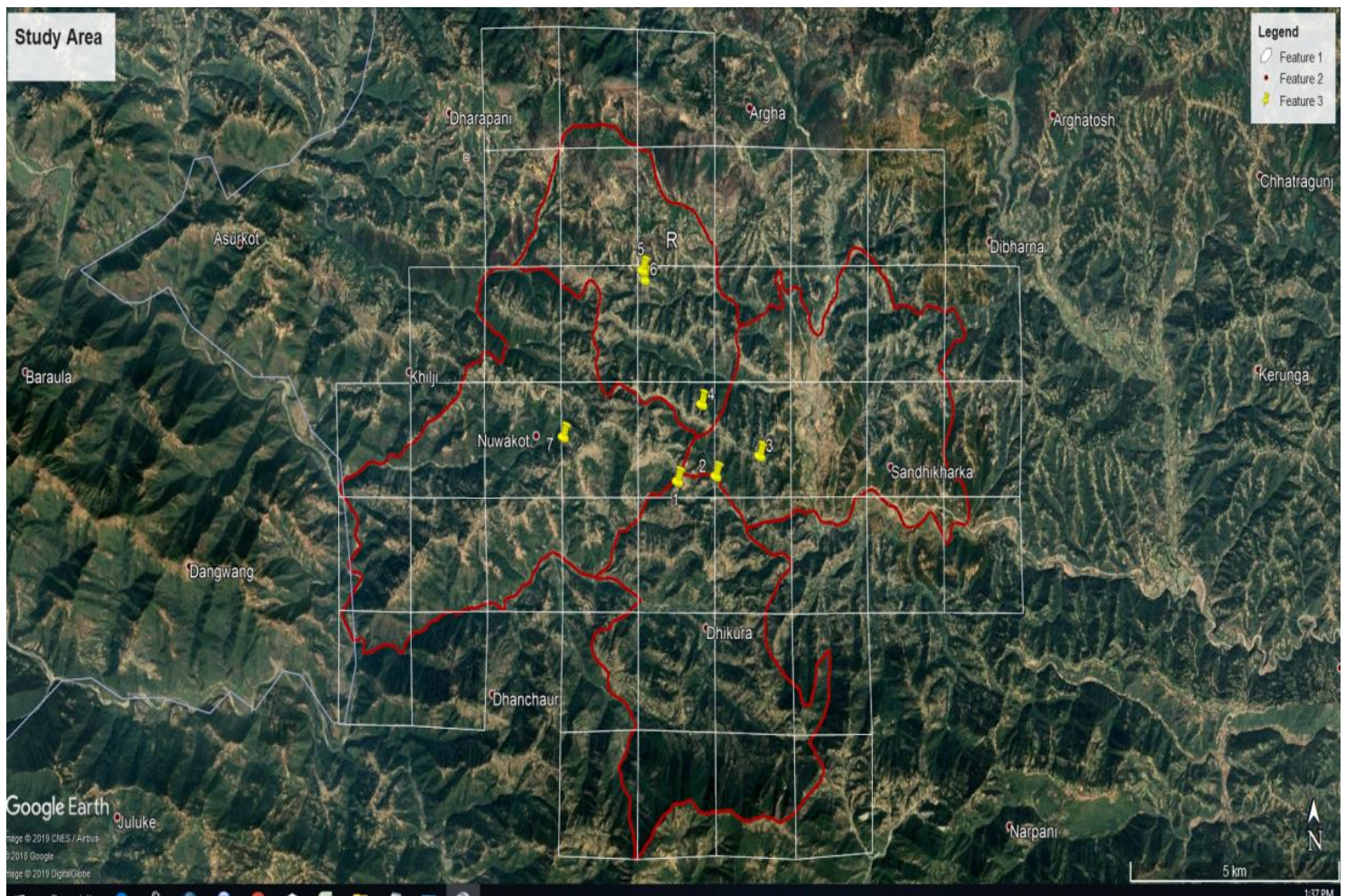

Figure 2: Camera station map showing the camera locations at Arghakhanchi

\section{Data analysis}

Depending on the photo capture rates of large carnivore and prey species a calculation was done in the index of relative abundance (RAI) as the number of days required for obtaining a photo capture of a species (Carbone, 2001). Only independent pictures of a particular species were counted as valid to estimate RAI. The independent photos resembles photos (Brien et al., 2006; Kinnaird et al., 2007;Wibisono et al.,2008) where each photo was identified to species and rated as dependent or independent event, with an 'independent capture event 'defined as (1) consecutive photographs of different individuals of the same or different species, (2) consecutive photographs of individuals of the same species taken more than $0.5 \mathrm{~h}$ apart and (3) non-consecutive photos of individuals of the same species were done where negative correlation of species abundance was seen as a useful tool to compare relative abundances of species, particularly when individuals of these species cannot be distinguished from each other. The use of histograms, graphs and pie-chart were done to show the results of social survey using Ms-excel. Similarly, for analyzing PCA (Principal Component Analysis) for the factors affecting Human- wildlife conflict, an assumption of twenty five factors with location and slope of the conflict locality to analyze the factors affecting the human leopard conflict was done.

They were: Frequency of leopard visit in year, Distance From Community Forest, Area of nearest forest, Distance of shrub from village, Nearest barren land, Nearest water source for 
Household use, Population Adult Male, Population Adult Female, Population Age Below 16, Population Age Above 50, Presence of private toilet, Distance of toilet from house, Distance of toilet from Nearest bush or forest, Stray dogs number, Livestock number, Shed feeding HH or graze feeding HH, Distance of shed from House, Crop type in houses, Domestic animalsdomesticated, Distance of grazing from house, Domestic animals-which attract leopard, Prey of leopard seen around village (List), Nearest water Source for wild animals from village, Land use change in last 5 years, Fencing in household. Total 44 villagers or household were questionnaire not repeated from single village or cluster of settlement.

\section{PCA analysis}

PCA is the simplest of the true eigenvector-based multivariate analyses. Often, its operation can be thought of as revealing the internal structure of the data in a way that best explains the variance in the data. If a multivariate dataset is visualized as a set of coordinates in a highdimensional data space (1 axis per variable), PCA can supply the user with a lowerdimensional picture, a projection of this object when viewed from its most informative viewpoint This is done by using only the first few principal components so that the dimensionality of the transformed data is reduced. CamtrapR and TRAPPER were the software which was used for the analysis. PCA is closely related to factor analysis.

\section{RESULTS}

\section{Prey diversity and abundance at the Study Area}

\section{Evaluating prey species and their number recorded in Camera Traps}

A total of 72 numbers of photographs were recorded belonging to five prey species of leopard (Mongoose, Wild cat, Rabbit, Porcupine and barking deer). There were total 72 independent photos of prey species. Similarly, one photo of leopard was recorded by camera. Among them, the recorded prey species were $12.5 \%$ of Mongoose, $37.5 \%$ of barking deer, $4.167 \%$ of porcupine, $2.78 \%$ of wild cat and $2.8 \%$ of wild rabbit.

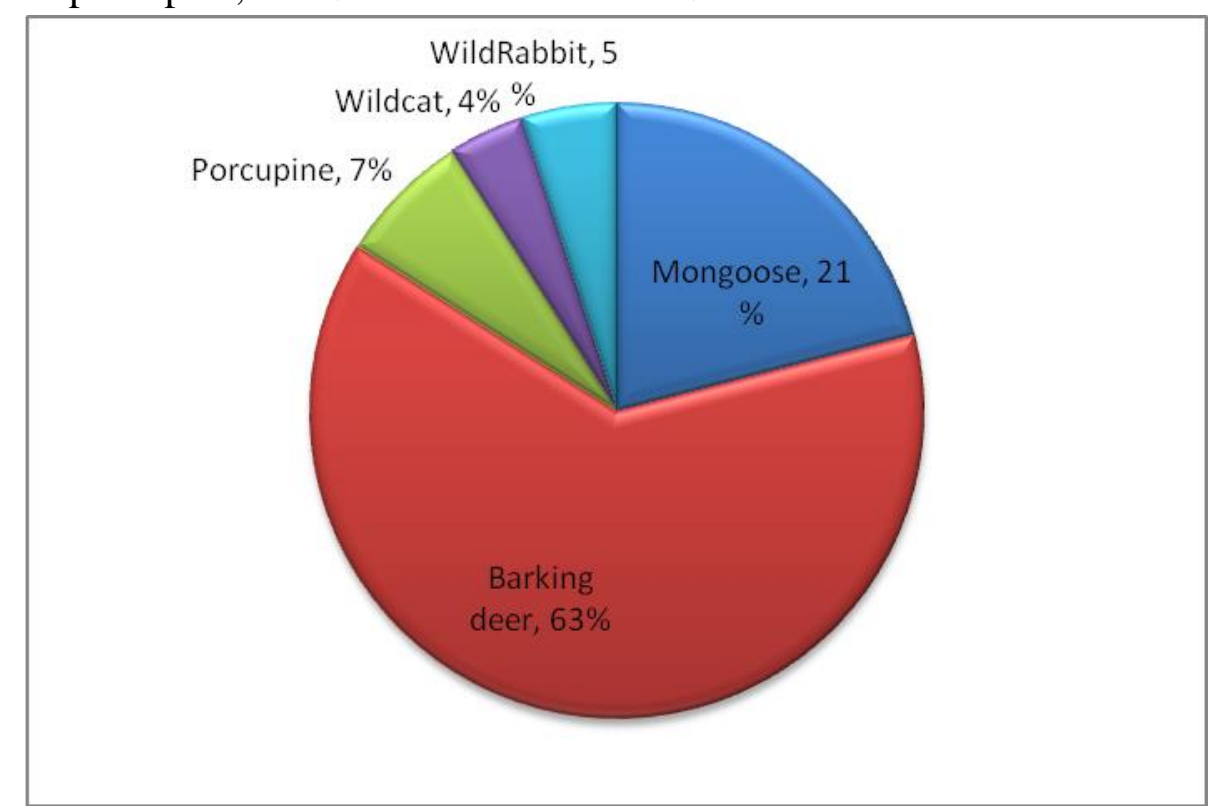

Figure 3: Prey abundance of Leopard

Human Leopard conflict in Arghakhanchi 
A total of 19 leopards were killed by people as a retaliation killing while a total of 14 people were killed by leopard within 6 years of time. Among the total leopard casualty there were 8 female leopards and 9 male leopards. However, 3 of the killed leopard were not identified.

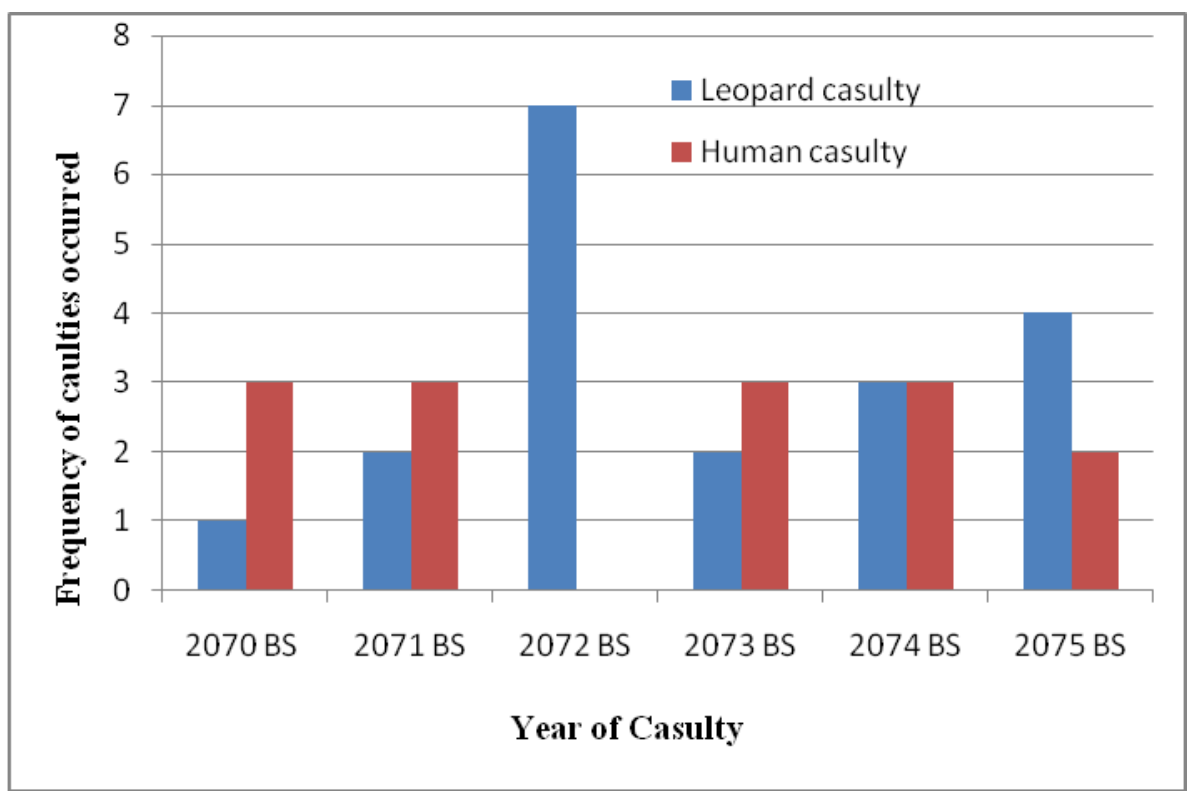

\section{Figure 4: Human and Leopard casualty}

Human and Leopard casualty with their respective genders.

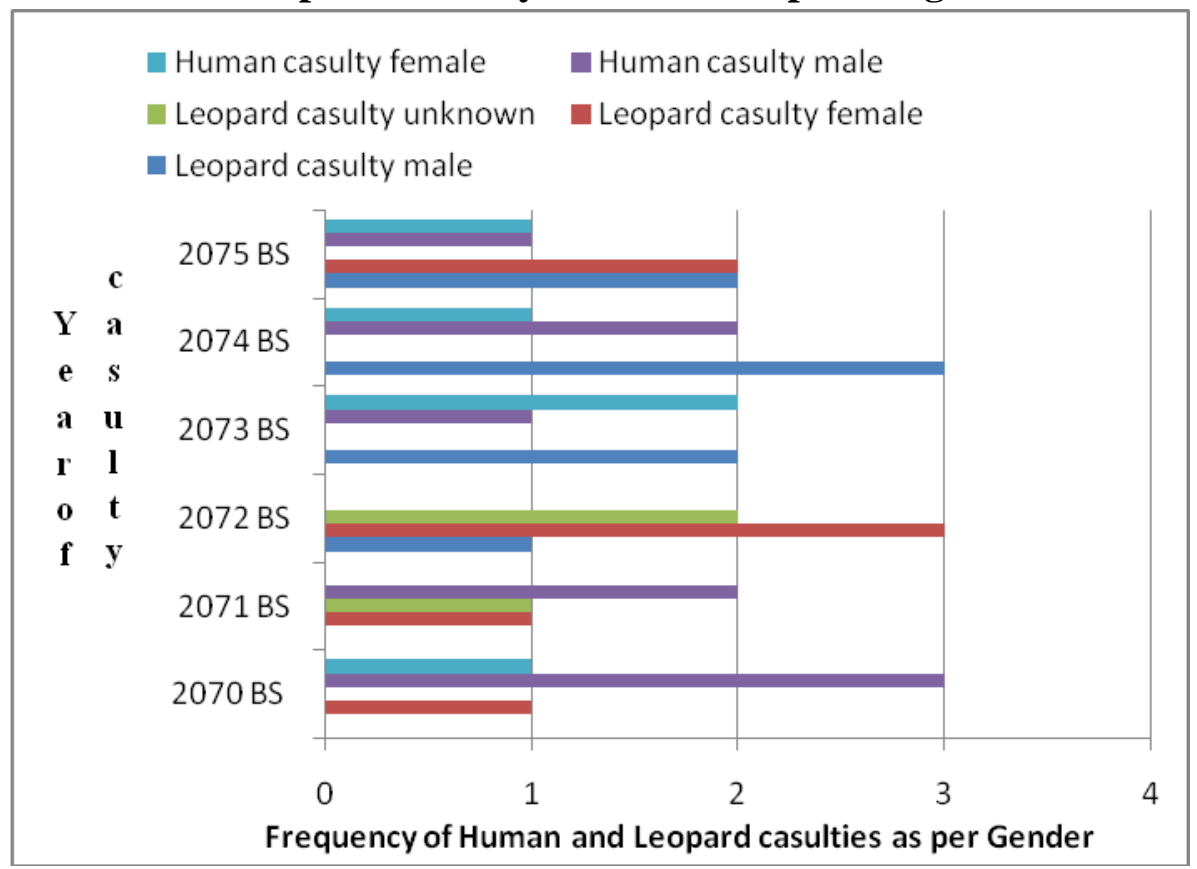

Figure 5: Human and Leopard casualty with male and female number

\section{Incidence occurrence of Leopard at Arghakhanchi}

Various incidence occurrence of Leopard were taken from Sandhikharka, Arghakhanchi through the means of secondary data collected from DFO, Arghakhanchi. The table below explains the number, date and the conditions of victim's information respectively. The information resembles the 25 attacks that were held since past 9 years at Arghakhanchi itself (Table 1). 
Table 1: Number and condition of Victims

\begin{tabular}{|c|c|c|}
\hline YEAR & Number of Victims Attacked & CONDITION \\
\hline 2067 & 2 & Wounded \\
\hline 2068 & 1 & Wounded \\
\hline 2070 & 3 & Killed \\
\hline 2071 & 5 & Both \\
\hline 2072 & 2 & Wounded \\
\hline 2073 & 5 & Both \\
\hline 2074 & 4 & Both \\
\hline 2075 & 3 & Both \\
\hline
\end{tabular}

Source: DFO Arghakhanchi, Sandhikharka, 2019

\section{Perception of Local People towards Leopard}

As one of the objectives of the research was to analyze and evaluate the perception of the local people at Arghakhanchi a perception test with five different questions relevant to the research were asked with the local people such as "If they think the conservation of leopard is important?" 91.4\% responded positively, $2.2 \%$ responded negatively and $6.5 \%$ were unknown about relation of this carnivore with environment, only $15 \%$ believed that conservation of it is important while $70 \%$ of the locals believed they shouldn't be conserved because of the human and livestock threat. However, $15 \%$ were unsure about their conservation.

Similarly, one of the major questions when asked to the locals about was "what should be done when a leopard is encountered"? Most of the respondents that is $70 \%$ of them believed that they should be killed, while $5 \%$ of the respondents believed that they should be informed to Divisional Forest office and the remaining 5\% believed to do nothing about this.

5 questions were asked to know the perception of local people towards leopard, $15 \%$ of the respondents believed that leopard were considered to have ethical values, 5\% believed that they balance ecosystem and $70 \%$ believed that these animal is threatening.

The variance in mean attitude of illiterate and literate toward leopards using ANOVA were tested and found that there was no significant difference between their mean attitudes toward leopards $(\mathrm{p}=0.61$ at $95 \%$ confidence interval) and both posses negative attitudes towards leopard.

\section{Assessing the Factors affecting HLC at Arghakhanchi}

\section{Assessment of the season of the Incident}

With the assessment of the attacks by leopard, it was clearly assumed that the season where leopard attacks were highly seen was in the month of August. 9 incidents have had happened in the month of August where there is a practice of cropping maize in the area. With the plantation and the growth of maize, the leopard could easily hide and travel to attack small children. However, the time differed from one victim to the other victim in the village. $25 \%$ of respondents responded that the attacks happened in the day time. In contrast, the rest reported that the attack was highly in the month of August but differing in time in the time after $7 \mathrm{pm}$. 
According to (DFO) as the secondary data source, the attack to two of the victim occurred twice. That is the same child was killed in the second attack by the leopard near the village after being wounded in the first attack.

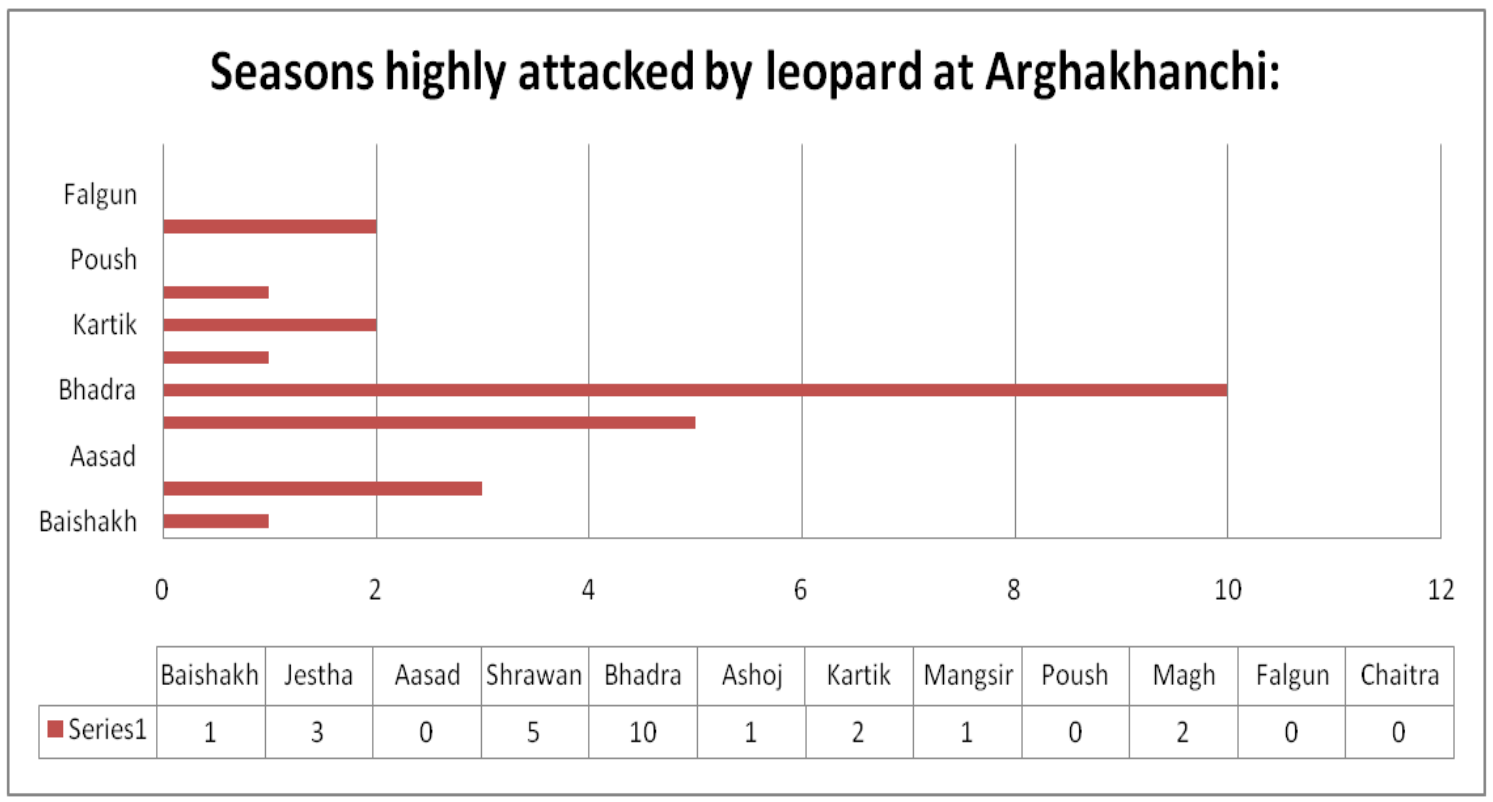

\section{Figure 6: Seasons attacked by Leopard}

\section{Distance of HH from Community Forest}

With the survey of 120 respondents, it was found out that the $\mathrm{HH}(30 \%)$ had a 300 meter distance from the nearby community forest. The majority of $\mathrm{HH}$ had their houses nearby to the community forest which could be a result of more attacks seen in the area.

Also HH being nearby to the community forest can be assumed to be more dangerous as it is considered as the territory of Leopard which keeps travelling.

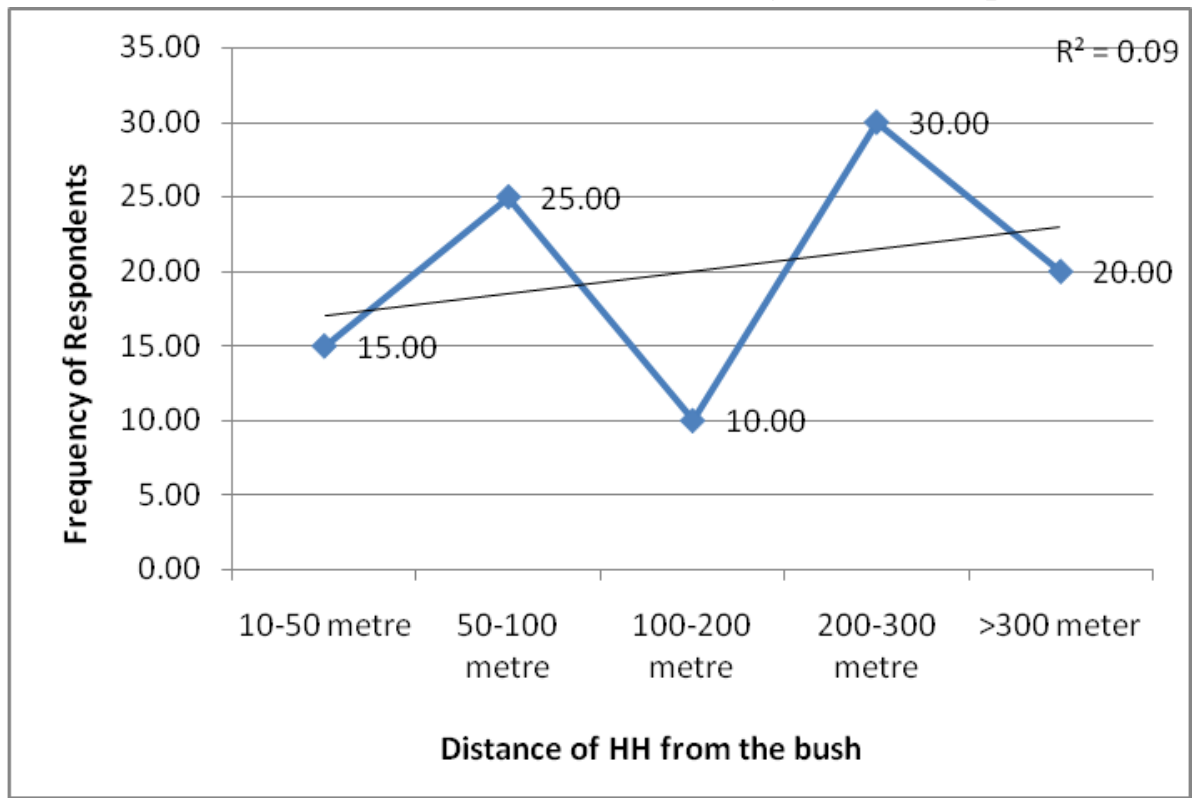

\section{Figure 7: Distance of Households from community forest}

Here, the correlation is 0.09 , and the $\mathrm{p}$ value is 0.6071 . The result is not significant at $\mathrm{p}<.10$ which means that the distance from the bush and the conflict is moderately correlated. 


\section{Fencing in the $\mathrm{HH}$}

In the study area, only $12 \%$ of the individuals had fencing at their households while $88 \%$ of the individuals had no fencing systems possessing risk to having houses in the forest area (Figure 11).

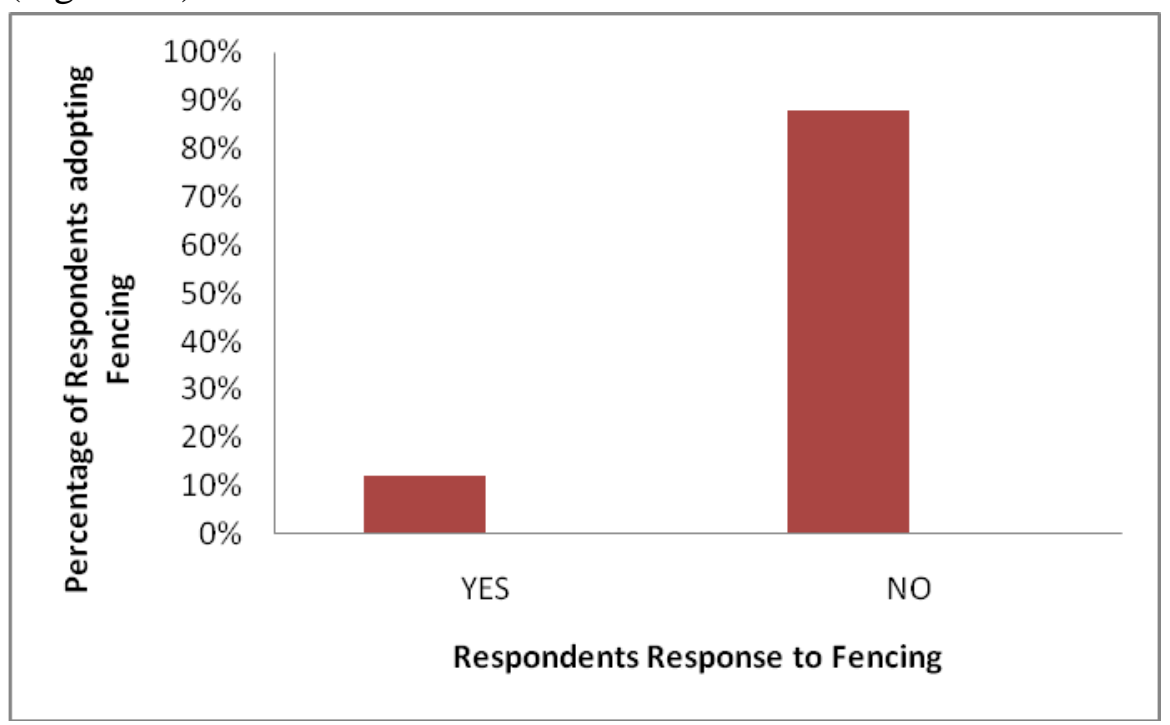

\section{Figure 6: Fencing in the HH}

The correlation between the frequency of Leopard occurrence and conflict is higher.

\section{Scoring system in assessing the Attitudes}

The overall attitudes of people were assessed giving them score as shown in Table 2 (Suryawanshi, 2014). We found overall mean attitude of illiterate people negative ($1.03 \pm 0.14 \mathrm{SE}$ ) towards leopard. Also, overall mean attitude of literate people is negative ($1.19 \pm 0.17 \mathrm{SE})$. The attitude of literate people is little more negative than illiterate people.

\section{Factors affecting Human Leopard Conflict}

The answer received is analyzed through PCA analysis to explore the most important factors that affect the human leopard conflict in the study area. The result suggested that the distance from water source to local people, distance from toilet to home, land use change going on in the study area, scarcity of water source to wildlife inside the forest, distance to graze livestock are major factors having positive impact (Increases the conflict between leopard and human) on human leopard conflict. While presence of children at home and forest distance doesn't play any role in conflict, fence around home, toilet away from bush, barren land plays negative role (reduce the conflict) to attract leopard to village. 


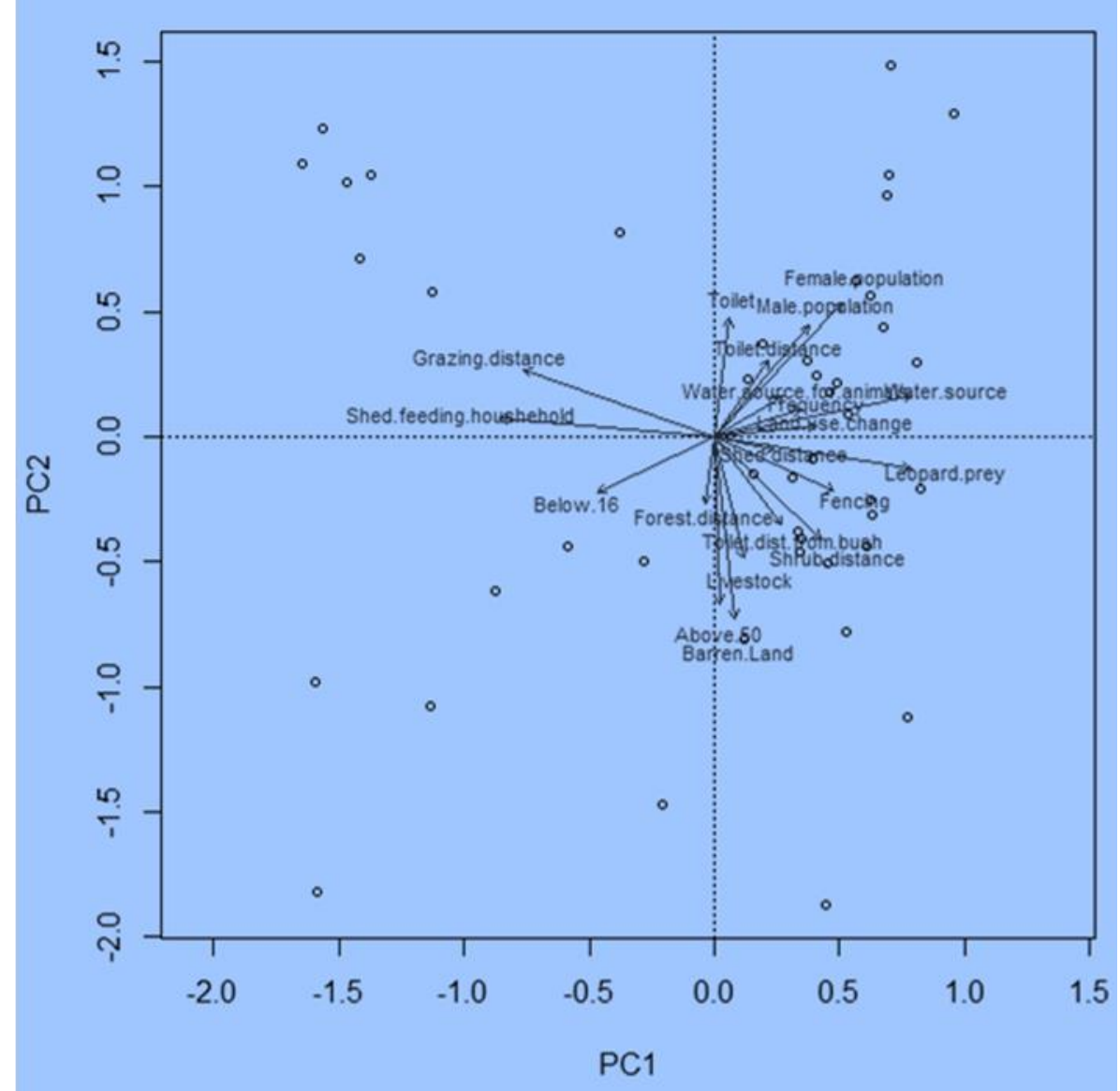

\section{Figure 9: PCA analyses of factors affecting Human leopard conflict}

Different PCA results have been recorded according to the different data received from the research survey. PCA analysis of different factors like forest distance, shrub distance, barren land, water source, male population, female population, toilet distance, toilet distance from the bush, shed feeding household, shed distance, grazing distance, land use change was analyzed where different results of factors were seen.

Different types of factors analysis were done to know the Principle component that triggered the conflict to the highest level. According to the factor analysis, the shrub distance was seen to be 0.50215, which shows that it has higher influence on Human Leopard Conflict. Similarly, the factor components as water sources and few population source also shows that they have higher influence on HLC. However, the barren land having (0.09829) has negative influence in HLC in respective to Principle component analysis.

\section{CONCLUSIONS}

According to our research regarding the prey abundance of common leopard, camera trap and interviews promulgated in knowing the prey abundance at Arghakanchi. Also, regarding the perception of local people, most of the respondents have negative attitude towards leopard conservation because of the massive amount of threat to their children along with the livestock. The treat was seen highly to the children at the village as they possessed as an easy prey for Leopard. Our study recommends launching awareness program regarding the importance of mitigation approaches such as using up of fence system, not having settlements in the forest area inclusion of "how to cope with situation when leopards enter in their 
settlement?" because overall respondent have negative attitude towards leopard regarding their conservation as known from the respondents responds.

Mitigation practices to reduce Human Leopard Conflict? According to the respondents and the data inculcated, the mitigation practices done by few of the respondents were the fencing system, used by very few people while other mitigation practices included cleaning of bushes around the village area where leopards tend to hide often. Because of the increasing status of leopard in recent years where number of live stocks and lives had been damaged it is very necessary to have an adequate mechanism by DFO to demolish the threat caused by leopard in the village.

\section{ACKNOWLEDGEMENTS}

We would like to thank Hariyo Ban Program, WWF NEPAL for providing the research grant along with DFO (Divisional Forest Office of Arghakhanchi) for providing a partial grant during the research period.

\section{REFRENECES}

Acharya, K. P., Paudel, P. K., Neupane, P. R., \& Köhl, M. (2016). Human-wildlife conflicts in Nepal: patterns of human fatalities and injuries caused by large mammals. PLoS one, 11(9), e0161717.

Aryal, A., David., \& Kanyal (2012). Summer diet composition of the common leopard Panthera pardus (Carnivora: Felidae) in Nepal. Journal of Threatened Taxa, 1(11), 562-566.

Athreya, V., Bhatia, A., Bhatnagar, G., \& Mishra (2004). Human- leopard guidelines. Unpublished Report. Kaati Trust, Pune, India.

Athreya, V., \& Belsare, A. (2007). Human-leopard conflict management guidelines. Unpublished Report. Kaati Trust, Pune, India.

Athreya, V., Odden, M., Linnell, J. D., \& Karanth, K. U., \& Zimmermann (2009). Translocation as a tool for mitigating conflict with leopards in human-dominated landscapes of India. Conservation Biology, 25(1), 133-141.

Athreya, V., Odden, M., Linnell, J. D., Krishnaswamy, J., \& Karanth, U. (2013). Big cats in our backyards: persistence of large carnivores in a human dominated landscape in India. PLoS one, 8(3), e57872.

Athreya, V., Srivathsa, A., Puri, M., Karanth, K. K., Kumar, N. S., \& Karanth, K. U. (2015). Spotted in the news: using media reports to examine leopard distribution, depredation,

and management practices outside protected areas in Southern India. PLoS One, 10(11), e0142647.

Awan., Ghoddousi., \& Kabir (2004). Leopard and its behavior, (11), 34-56

Bagchi, S., \& Mishra, C. (2006). Living with large carnivores: predation on livestock by the snow leopard (Uncia uncia). Journal of zoology, 268(3), 217-224.

Bailey, T. N. (1993). The African leopard: ecology and behavior of a solitary felid: Columbia University Press.

Barlow, Gurung., \& McDougal (2006) Hunter,L., \& Impact of conservation interventions on dynamics, 149 (12) , 1234-3456

Brien, G., Kinnaird., H, Wibisono., J. (2008). The use of photographic rates to estimate densities of tigers and other cryptic mammals. 
Bjerke, T., Kaltenborn, B. P., \& Thrane, C. (2001). Sociodemographic correlates of fearrelated attitudes toward the wolf(Canis lupus lupus). A survey in southeastern Norway. Fauna Norvegica, 21, 25-33. 16

Boulhosa, Faria., Michalski., \& Presco ( 2009) (13). Causes of fragmentation of wildlife habitat, 234-456

Bhatia., Bhatnagar., Redpath., \& Suryawanshi ( 2015). Attitude scores of peoples perception. 456

123-100

Carbone, C., (2001). The use of photographic rates to estimate densities of tigers and other cryptic mammals. Paper presented at the Animal Conservation Fórum.

Carbone, C., Christie, S., Conforti, K., Coulson, T., Franklin, N., Ginsberg, J., . . Kinnaird, M. (2001). The use of photographic rates to estimate densities of tigers and other cryptic mammals. Paper presented at the Animal Conservation Fórum.

Chapron., Dickman., \& Hazzah (2009). Conserving carnivores: politics in play. Science, 343(6176), 1199-1200.

CITES. (2016). Home Documents. https://cites.org/sites/default/files/eng/app/2016/E-Appendices-2016-03-10.pdf

Dar (2009). Rural livelihood and Human Wildlife Conflicts, 45, 234-554

Dar, N. I., Minhas, R. A., Zaman, Q., \& Linkie, M. (2009). Predicting the patterns, perceptions and causes of human-carnivore conflict in and around Mahiara National Park, Pakistan. Biologial Conservation, 2076-2082.

DFRS. (2015). Middle Mountains Forests of Nepal, Forest Resource Assessment (FRA) Nepal. Kathmandu: Department of Forest Research and Survey.

Dickman, A. J., Madden.,Paterson (2005). Complexities of perceptions in interaction: the importance of considering social factors for effectively resolving human-wildlife conflict. Animal conservation, 13(5), 458-466.

Dickman, A. J., Hazzah, L., Carbone, C., \& Durant, S. M. (2014). Carnivores, culture and 'contagious conflict': Multiple factors influence perceived problems with carnivores in Tanzania's Ruaha landscape. Biological conservation, 178, 19-27.

DNPWC. (2014). Annual Report. Kathmandu.

DNPWC. (2017a). Profiling of Protected and Human Wildlife Conflicts Associated Wild Animals in Nepal. Kathmandu: Department of National Parks and Wildlife Conservation.

DNPWC. (2017b). Profiling of Protected and Human Wildlife Conflicts Associated Wild Animals in Nepal. Kathmandu: Department of National Parks and Wildlife Conservation.

Dowie, ( 2011) M., Rabinowitz., Thirgood., \& Woodroffe (2002). Conservation refugees: the hundred-year conflict between global conservation and native peoples: mit Press.

Frank, Ole Ranah., Lindsey., Woodroffe ( 2004). Wildlife Conflicts and Biological Conservation, 198,23-28.

Gautam, B ( 2004). Mountain water shed in central Nepal., 23, 56-66 17

Gurung, B., Smith, J. L. D., McDougal, C., Karki, J. B., \& Barlow, A. (2008). Factors associated with human-killing tigers in Chitwan National Park, Nepal. Biological Conservation, 141(12), 3069-3078.

Haack, B. N., \& Rafter, A. (2006). Urban growth analysis and modeling in the Kathmandu valley, Nepal. Habitat International, 30, 1056-1065. 
Henschel (2015). People and leopards conflict. 12, 23-45

Henschel, P., Hunter, L., Breitenmoser, U., Purchase, N., Packer, C., Khorozyan, I., . . . Wursten, C. B.-. (2015). Home > Panthera pardus (Leopard). www.iucnredlist.org. http://www.iucnredlist.org/details/15954/0

Inskip, C., \& Zimmermann, A. (2009). Human-felid conflict: a review of patterns and priorities worldwide. Oryx, 43(1), 18-34.

Jacobson, A. P., Gerngross, P., Jr., J. R. L., Schoonover, R. F., Anco, C., Wursten, C. B., . . . Stein, A. B. (2016). Leopard (Panthera Pardus) status, distribution, and the research efforts accross its range. PeerJ, 4(e).

Kabir, M., Ghoddousi, A., Awan, M. S., \& Awan, M. N. (2013). Assessment of humanleopard conflict in Machiara National Park, Azad Jammu and Kashmir, Pakistan. European journal of wildlife research, 60(2), 291-296. doi: 10.1007/s10344-0130782-z

Kaltenborn, F., Thrane, G. ( 2001). Attitudes towards leopard. 60(5), 345-566

Karanth, K., \& Madhusudan, M. (2002). Mitigating human-wildlife conflicts in southern Asia. In J. Terborth, L. Davenport \& M. Rao (Eds.), Making Parks Work: Identifying key factors to implementing parks in the tropics (pp. 250-264). Washington DC: Island Press.

Karanth, K. U., \& Chellam, R. (2009). Carnivore conservation at the crossroads. Oryx, 43(1), $1-2$.

KC, B. ( 2018, November 8). Leopard attacks on children increase in Arghakhanchi The Kathmandu Post. Retrieved from http://kathmandupost.ekantipur.com/printedition/news/2018-11-08/leopard-attackson-children-increase-in-arghakhanchi.html ( Online portal)

Kendall.,Knuth (2009). Consequences of wildlife conflict.Oryx, 23 (2),3-5

Koirala, R. K., Aryal, A., \& Parajuli andDavid, A. (2012). Human-common leopard (Panthera pardus) conflict in lower belt of Annapurna Conservation Area, Nepal. Journal of Research in Conservation Biology, 1(1), 5-12.

Kretser, H. E., Curtis, P., Francis, J. D., Pendall, R. J., \& Knuth, B. A. (2009). Factors affecting perceptions of human-wildlife interactions in residential areas of northern New York and implications for conservation. Human Dimensions of Wildlife, 14(2), 102-118.

Lee, J. W., Jones, P. S., Mineyama, Y., \& Zhang, X. E. (2002). Cultural differences in responses to a Likert scale. Research in nursing \& health, 25(4), 295-306. 18

Linnell, J. D., Swenson, J. E., \& Anderson, R. (2001). Predators and people: conservation of large carnivores is possible at high human densities if management policy is favourable. Paper presented at the Animal Conservation forum.

Madden, F. (2004). Creating coexistence between humans and wildlife: global perspectives on local efforts to address human-wildlife conflict. Human dimensions of wildlife, 9(4), 247-257.

Michalski (2006). Determinants of Human wildlife conflicts, 8, 23-45

Michalski, F., Boulhosa, R. L. P., Faria, A., \& Peres, C. A. (2006). Human-wildlife conflicts in a fragmented Amazonian forest landscape: determinants of large felid depredation on livestock. Animal Conservation, 9, 179-188. 
Mineyama., Zang.,F (2002). Attitude score testing in conflict of wildlife 8, 234-456

Mizutani, F. (1990). Biomass density of wild and domestic herbivores and carrying capacity on a working ranch in Laikipia District, Kenya. African Journal of Ecology, 37(2), 226-240.

Morina, B. (2015). Implementation of ICT against corruption in the higher education of Kosovo.

Morrison, C. D., Boyce, M. S., Nielsen, S. E., \& Bacon, M. M. (2014). Habitat selection of a re-colonized cougar population in response to seasonal fluctuations of human activity. The Journal of Wildlife Management, 78(8), 1394-1403. National Population and Housing Census (2011). Government of Nepal.

O'Brien, T. G., Kinnaird, M. F., \& Wibisono, H. T. (2003). Crouching tigers, hidden prey: Sumatran tiger and prey populations in a tropical forest landscape. Paper presented at the Animal Conservation forum.

Patterson, B. D., Kasiki, Yaken., S. M., Selempo, E., \& Kays, R. W. (2004). Livestock predation by lions (Panthera leo) and other carnivores on ranches neighboring Tsavo National Parks, Kenya. Biological Conservation, 119(4), 507-516.

Peterson, M. N., Birckhead, J. L., Leong, K., Peterson, M. J., \& Peterson, T. R. (2010). Rearticulating the myth of human-wildlife conflict. Conservation Letters, 3(2), 74-82.

Pokharel, M. (2015). Human-Leopard Conflict in the Kathmandu Valley, Nepal.

Saxena, K. (2004). Patterns and ecological implications of agricultural land- use changes, 3455.

Saxena, K. G., Semwal, R. L., Nautiyal, S., Sen, K. K., Rana, U., Maikhuri, R. K., \&Rao, K. S. (2004). Patterns and ecological implications of agricultural land-use changes: a case study from central Himalaya, India. Agriculture, Ecosystems and Environment, 102, 81-92.

Schaller, G. B. (1983). Mammals and their biomass on a Brazilian ranch. Arquivos de Zoologia (Sao Paulo), 31(1), 1-36.

Seidensticker, J. (1990). Leopards living at the edge of the Royal Chitwan National Park, Nepal. Conservation in developing countries: Problems and prospects, 415-423.

Shrestha, T. K. (2003). Wildlife of Nepal. Kathmandu: Curriculum Development Centre Tribhuvan University.

Silveira, L., Jacomo, A. T., \& Diniz-Filho, J. A. F. (2003). Camera trap, line transect census and track surveys: a comparative evaluation. Biological conservation, 114(3), 351355.

Stein, A., Athreya, V., Gerngross, P., Balme, G., Henschel, P., Karanth, U., . . Laguardia, A. (2017). Panthera pardus.(errata version published in 2016) The IUCN Red List of Threatened Species 2016: e. T15954A102421779. Downloaded on, 15.

Suryawanshi, K. R., Bhatia, S., Bhatnagar, Y. V., Redpath, S., \& Mishra, C. (2014). Multiscale factors affecting human attitudes toward snow leopards and wolves. Conserv Biol, 28(6), 1657-1666. doi: 10.1111/cobi.12320

Suryawanshi, K. S., Bhatia, S., Bhatnagar, Y. V., Redpath, S., \& Mishra, C. (2014). Multiscale Factors Affecting Human Attitudes toward Snow Leopards and Wolves. Conservation Biology, 00(0), 1-10.

Thapa, R. B., \& Murayama, Y. (2012). Scenario based urban growth allocation in Kathmandu valley, Nepal. Landscape and Urban Planning, 105(1-2), 140-148. 
Thapa, T. B. (2014). Human Caused Mortality in the Leopard (Panthera pardus) Population of Nepal. Journal of Institute of Science and Technology, 19(1), 155-150.

Treves, A., \& Karanth, K. U. (2003). Human-carnivore conflict and perspectives on carnivore management worldwide. Conservation Biology, 17(6), 1491-1499. 